\title{
Comparative effects of pressure support ventilation and intermittent positive pressure breathing (IPPB) in non-intubated healthy subjects
}

\author{
J. Mancebo+, D. Isabey*, H. Lorino*, F. Lofaso*, F. Lemaire*, L. Brochard*
}

Comparative effects of pressure support ventilation and intermittent positive pressure breathing (IPPB) in non-intubated healthy subjects. J. Mancebo, D. Isabey, H. Lorino, F. Lofaso, F. Lemaire, L. Brochard. COERS Journals Ltd 1995.

ABSTRACT: We compared the efficacy of three devices delivering assisted noninvasive ventilation with different working mechanisms, during room air breathing and during $\mathrm{CO}_{2}$-induced hyperventilation.

In seven healthy volunteers, breathing pattern, respiratory muscle activity and comfort were assessed: during unassisted spontaneous breathing through a mouthpiece (SB); during assisted breathing with a device delivering inspiratory pressure support (IPS); and with two devices delivering intermittent positive pressure breathing (IPPB), the Monaghan 505 (IPPB1), and the CPU 1 ventilator (IPPB2). All three devices were set at $10 \mathrm{cmH}_{2} \mathrm{O}$ of maximal pressure.

During room air breathing, the work of breathing expressed as power, was significantly greater with the two IPPB devices than with the two other modes (IPPB1 and IPPB $27.3 \pm 5.2$ and $7.2 \pm 6.2 \mathrm{~J} \cdot \mathrm{min}^{-1}$, respectively, versus $\mathrm{SB}$ and IPS $2.4 \pm 0.7$ and 2.3 $\pm 3.3 \mathrm{~J} \cdot \mathrm{min}^{-1}$, respectively). The difference did not reach the statistical significance for the pressure-time product (PTP). Discomfort was also greater during the IPPB modes. During $\mathrm{CO}_{2}$-induced hyperventilation, considerable differences in power of breathing were found between the two IPPB devices and the other two modes. The PTP was also much higher with IPPB. Transdiaphragmatic pressure was significantly smaller during IPS than during the three other modes (IPS 18 \pm 2.6 $\mathrm{cmH}_{2} \mathrm{O}$ versus SB 22 \pm 2.6 , IPPB1 32 \pm 5.2 , and IPPB2: 28 \pm 5.2 ). Maximal discomfort was observed during the IPPB modes and was correlated with the magnitude of transdiaphragmatic pressure $(r=\mathbf{- 0 . 6 0})$.

Despite similarities in their operational principles, IPS and IPPB had very different effects on respiratory muscle activity in healthy non-intubated subjects. IPPB machines not only failed to reduce patient's effort but also induced a significant level of extra work by comparison to spontaneous ventilation at ambient pressure. Great caution is, therefore, needed in the use of patient-triggered devices for nonintubated patients with acute respiratory failure.

Eur Respir J. 1995, 8, 1901-1909.
*Service de Réanimation Médicale and INSERM U296, Hôpital Henri Mondor, Créteil, France. +'Servei de Medicina Intensiva, Hospital de Sant Pau, Barcelona, Spain.

Correspondence: L. Brochard

Réanimation Médicale

Hôpital Henri Mondor

94010 Créteil cedex

France

Keywords: Acute respiratory failure intermittent positive pressure breathing mechanical ventilation

noninvasive ventilation pressure support ventilation work of breathing

Received: February 71994

Accepted after revision June 191995

J.M. was supported by grants from Fondo de Investigaciones Sanitarias de la Seguridad Social (88-2308), Spain, and from Fondation pour la Recherche Médicale, France.
Intermittent positive pressure breathing (IPPB) has been proposed in non-intubated patients with the aim of reducing the work of breathing and improving arterial blood gases [1-4]. In addition, it has been used as a tool to improve lung mechanics in patients with respiratory muscle weakness and to prevent postoperative complications in patients undergoing abdominal surgery [5-7]. Although the results of numerous studies evaluating the efficacy of this method have been disappointing, it is still used in clinical practice in the postoperative period [6].

Inspiratory pressure support (IPS) is a recent mode of inspiratory assistance, which resembles IPPB in that cycles are triggered by the patient, both methods are pressuretargeted and both have been proposed for non-intubated subjects [1-9]. IPS has been used for intubated patients in the process of weaning from mechanical ventilation, allowing a reduction in the work and oxygen cost of breathing [10-12]. It has also been used for patients with chronic obstructive pulmonary disease who were admitted for acute respiratory failure, as a means of avoiding tracheal intubation $[8,9]$.

The IPS and IPPB methods are both designed to provide a mechanical aid to lung expansion by assisting inspiration. However, they differ because with IPS a plateau pressure level is maintained during the entire inspiration by servocontrol of the inspiratory flow. Also, their cycling mechanisms from inspiration to expiration are different. Various devices are now proposed for performing noninvasive ventilation, with little evaluation of their respective physiological effects. We therefore wondered how far technical differences affect their efficacy 
in non-intubated subjects. We measured the work and effort of breathing and ventilatory pattern in normal subjects, during room air breathing and during a period of $\mathrm{CO}_{2}$-induced hyperventilation, whilst they were successively connected to one IPS and two IPPB machines. We found that considerable extra work was induced by IPPB devices.

\section{Subjects and methods}

All subjects gave their informed consent to participate in this investigation. The protocol had been approved by the Ethics Committee of Henri Mondor hospital.

Seven normal nonsmoking volunteers, 5 males and 2 females (mean age 29 yrs, range 24-35 yrs), were studied whilst sitting comfortably in an armchair. All were physicians and four were considered as naive with regard to the apparatus and modes of ventilation studied. The subjects breathed with a noseclip, through a mouthpiece attached to a pneumotachograph. They were instructed to place their hands on their cheeks during the application of positive pressure.

\section{Measurements}

Airflow $\left(V^{\prime}\right)$ at the mouth was measured with a heated Fleisch No. 2 pneumotachograph connected to a differential pressure transducer (Validyne $\mathrm{DP} 45 \pm 2.5 \mathrm{cmH}_{2} \mathrm{O}$, Northridge, CA, USA), and volume was obtained by electrical integration of the flow signal. The pneumotachograph was calibrated with a $1 \mathrm{~L}$ syringe containing room air.

Airway pressure $(P$ aw $)$ was recorded at the airway opening with a differential pressure transducer (Validyne DP45 $\pm 70 \mathrm{cmH}_{2} \mathrm{O}$, Northridge, CA, USA). To measure oesophageal $(P$ oes $)$ and gastric $(P$ ga $)$ pressure, two thin latex balloons attached to a double lumen polyethylene catheter were introduced through the nostril after topical anaesthesia; each was connected to a differential pressure transducer (Sensym SDX001, $\pm 70 \mathrm{cmH}_{2} \mathrm{O}$, Santa Clara, CA, USA). The oesophageal and gastric balloons were filled with 0.5 and $1 \mathrm{~mL}$ of air, respectively, and were secured to the nose with tape after its appropriate placement had been verified by an occlusion test [13]. Transdiaphragmatic pressure $(P \mathrm{di})$ was derived by electrical subtraction of $P_{\text {oes }}$ from $P$ ga. When present, expiratory positive $P_{\text {ga }}\left(P_{\text {ga,exp }}\right)$ was measured as the value of the positive swing from its minimal expiratory level to the maximal expiratory level before endexpiratory decay. The expired fraction of $\mathrm{CO}_{2}\left(\mathrm{FE}, \mathrm{CO}_{2}\right)$ was continuously monitored by means of an infra-red $\mathrm{CO}_{2}$ analyser (Gould capnograph IV, Bilthoven, The Netherlands) which sampled gas at the mouthpiece.

The expiratory line resistance of the different machines was measured in vitro by computing pressure-flow relationship at different levels of expiratory airflow with the ventilators connected to a constant flow source.

\section{Procedures}

The following four modes of ventilation were randomly studied, in two steps, during room air breathing and during $\mathrm{CO}_{2}$-induced hyperventilation.

Spontaneous breathing (SB). Subjects breathed room air through the mouthpiece connected to the pneumotachograph.

Inspiratory pressure support (IPS). The pneumotachograph was connected to the Y-piece of the apparatus providing IPS. This device was specially designed in our laboratory to provide IPS with the following features: flow-triggering with high sensitivity; ability to maintain a plateau pressure over a large range of flow rates; and low expiratory resistance. The inspiratory part of the circuit is pressurized during inspiration by injection of compressed air into a tube open to the atmosphere. The air entrainment mechanism allows a plateau pressure to be achieved which is maintained over a large range of flow rates [9]. The flow trigger sensitivity is $1 \mathrm{~L} \cdot \mathrm{min}^{-1}$, and the assistance is stopped when an adjustable level of decelerating flow is reached (here, a fixed threshold level of $15 \mathrm{~L} \cdot \mathrm{min}^{-1}$ was used). Expiration occurs through a large pneumatic expiratory valve, whilst the inspiratory part of the circuit is closed by a one-way valve. The level of IPS was set at $10 \mathrm{cmH}_{2} \mathrm{O}$. IPS was flow-triggered, pressure-limited and flow-cycled.

IPPB1. The first apparatus allowing the delivery of IPPB was the Monaghan 505 (Monaghan, Plattsburgh, NY, USA) set at a cycling pressure of $10 \mathrm{cmH}_{2} \mathrm{O}$ and at its maximal flow rate (over $85 \mathrm{~L} \cdot \mathrm{min}^{-1}$ with a decelerating flow pattern). IPPB1 was pressure-triggered, flow-limited and pressure-cycled.

$I P P B 2$. The second apparatus was the CPU 1 ventilator (Ohmeda, Maurepas, France) set in the barometric mode with an inspiratory flow of $40 \mathrm{~L} \cdot \mathrm{min}^{-1}$ (constant flow pattern), at a cycling pressure of $10 \mathrm{cmH}_{2} \mathrm{O}$ with a trigger sensitivity at its minimum level. IPPB2 was pressure-triggered, flow-limited and pressure-cycled.

Randomization was performed twice: firstly to determine whether air or $\mathrm{CO}_{2}$ was used for the first four periods, and secondly to determine the order of the modes of ventilation during each period. During $\mathrm{CO}_{2}$-induced hyperventilation, a special adaptor was used to connect the pneumotachograph to the Y-piece of the ventilator, and pure $\mathrm{CO}_{2}$ was added at a constant flow rate. $F \mathrm{E}, \mathrm{CO}_{2}$ was continuously monitored and the additional flow rate of $\mathrm{CO}_{2}$ was adjusted to keep end-tidal $\mathrm{CO}_{2}$ between 6 and $7 \%$. Special care was taken to ensure the same $F \mathrm{E}, \mathrm{CO}_{2}$ level for each subject during the four modes of ventilation. Each period lasted for $20 \mathrm{~min}$ and recordings were performed during the last $5 \mathrm{~min}$. After the end of each period, the subject was asked to complete a test to estimate subjective comfort, using a modified Borg scale to evaluate sensation of dyspnoea during the 
different procedures [14]. Maximum breathing comfort was scored as 10 and maximal discomfort as zero. The complete procedure lasted about $3 \mathrm{~h}$ for each subject.

\section{Calculations}

The signals of flow, tidal volume, $P$ aw, $P$ oes, $P$ ga and $F \mathrm{E}, \mathrm{CO}_{2}$ were recorded on a six-channel recorder (Gould Brush 260, Cleveland, OH, USA), and a typical example is shown in figure 1. The signals of flow, $P$ aw, and $P$ oes were also digitized at $32 \mathrm{~Hz}$ and sampled with an Apple IIe microprocessor system, which calculated the following from the flow signal: tidal volume, respiratory rate, minute ventilation, inspiratory time $(t \mathrm{I})$, the ratio of $t \mathrm{I}$ to total breath duration ( $\left.t \mathrm{I} / t_{\mathrm{tot}}\right)$, and peak inspiratory flow ( $V$ I, max).

The work of breathing was also computed automatically for each breath, and expressed as the area enclosed between the inspiratory part of a tidal pressure-volume loop on the one hand and the relaxation curve of the chest wall on the other [15]. The relevant pressure was oesophageal pressure, and the volume, inspiratory tidal volume. The chest wall relaxation curve was assumed to be linear and to have a slope corresponding to the predicted value for chest wall compliance in normal subjects (i.e. $4 \%$ of the predicted vital capacity per $\mathrm{cmH}_{2} \mathrm{O}$ )

A)
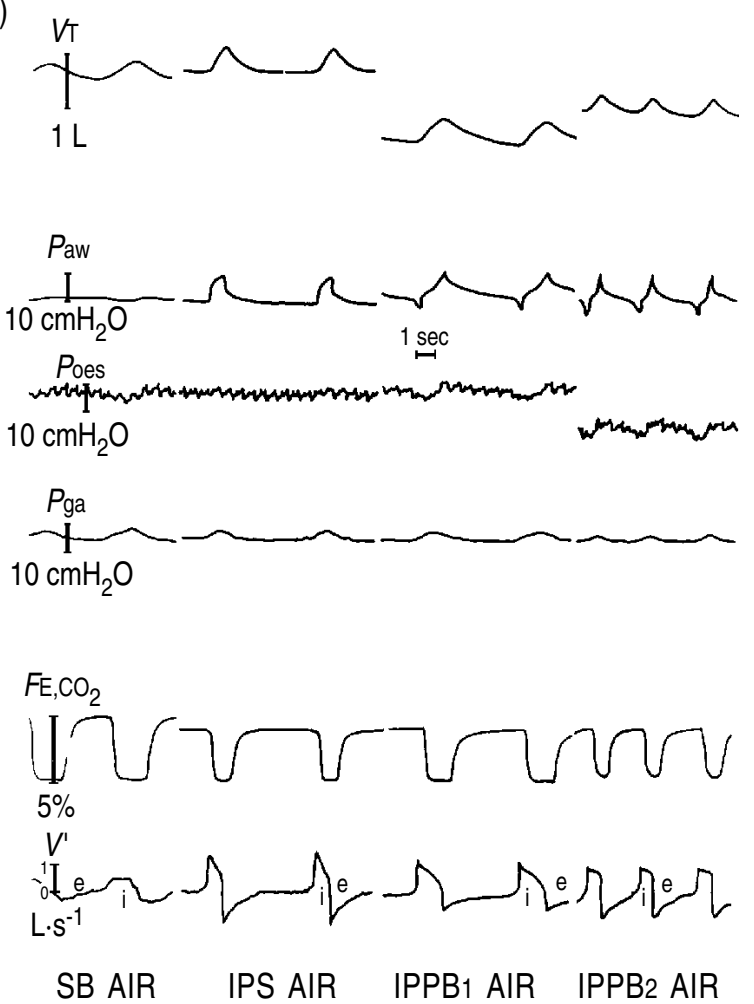

[16]. A Campbell diagram was constructed by passing this line through the end-expiratory elastic recoil pressure of the chest wall. When the total inhaled volume is exhaled and the relaxation volume of the respiratory system is reached, end-expiratory elastic recoil pressure of the chest wall is equal to the oesophageal pressure at the beginning of inspiration. In case of dynamic hyperinflation, when the equilibrium state is not reached at the end of expiration, additional pressure is generated by gas trapping, i.e. intrinsic positive end expiratory pressure or auto-PEEP (PEEPi). Dynamic PEEPi was calculated from the oesophageal pressure tracing as the sudden decline in pressure that occurs before the zero flow point, as described previously $[12,16]$. In this case, the chest wall relaxation line is passed through the value of chest wall elastic recoil pressure at the end of expiration, estimated as dynamic PEEPi. Values of $P$ di were calculated as the tidal $P$ di excursions. The oesophageal pressure-time product (PTP) was measured as the surface enclosed within the oesophageal pressure and the static recoil pressure line of the chest wall over inspiratory time, taking dynamic PEEPi into account.

Here, the combination of high minute ventilation and high expiratory resistance of the apparatus, induced the appearance of dynamic PEEPi during the $\mathrm{CO}_{2}$-induced hyperventilation step. However, since expiratory muscle activity was also present during $\mathrm{CO}_{2}$-induced hyperventilation, we reasoned that part of the dynamic PEEPi

B) $\quad V$<smiles>CCCCCCCCCCCCCCCCCCCCCCCCCC([Al])([Al])[Al]</smiles>
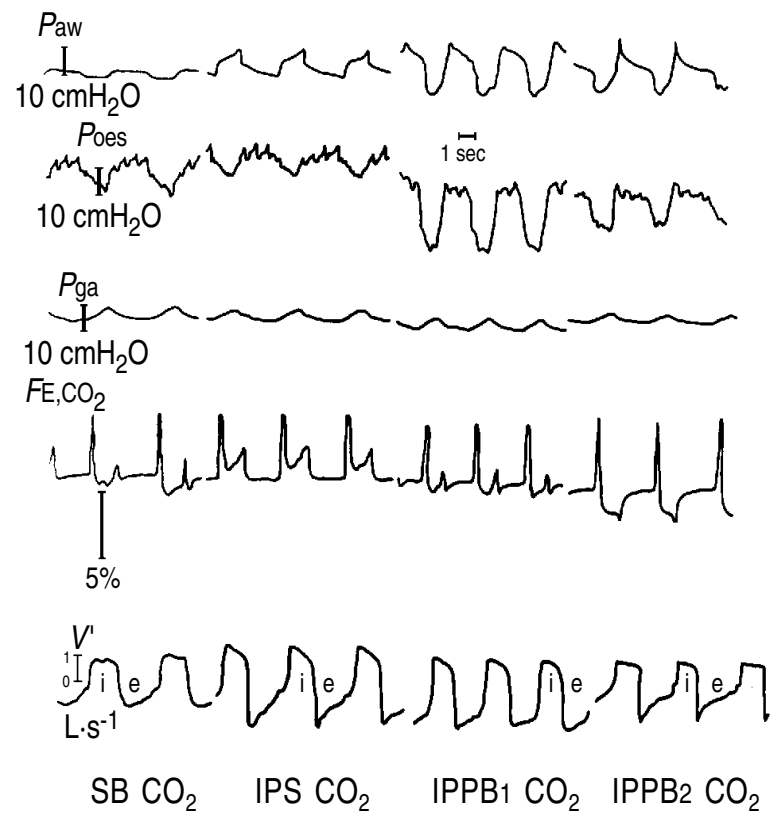

Fig. 1. - Tracings of tidal volume $(V \mathrm{~T})$, airway pressure $(P \mathrm{aw})$, oesophageal pressure $\left(P_{\mathrm{oes}}\right)$, gastric pressure $\left(P_{\mathrm{gaa}}\right)$, expired fraction of $\mathrm{CO}_{2}\left(F_{\mathrm{E}, \mathrm{CO}}\right)$, and airflow $\left(V^{\prime}\right)$ obtained from a representative subject during the four periods of unassisted breathing (SB, spontaneous breathing) or assisted breathing with inspiratory pressure support (IPS) or intermittent positive pressure breathing with a Monaghan 505 apparatus (IPPB1), or an Ohmeda CPU 1 ventilator (IPPB2). A) The four runs performed during room-air breathing (AIR). B) The four runs performed during $\mathrm{CO}_{2}$-induced hyperventilation $\left(\mathrm{CO}_{2}\right)$. Inspiration (i) and expiration (e) are indicated in the airflow tracings. 
A)

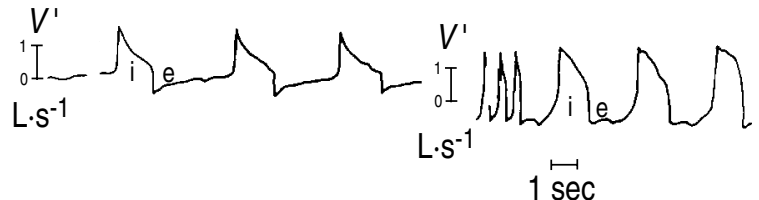

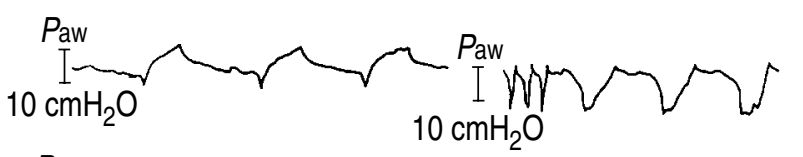

$$
\text { Poes }
$$

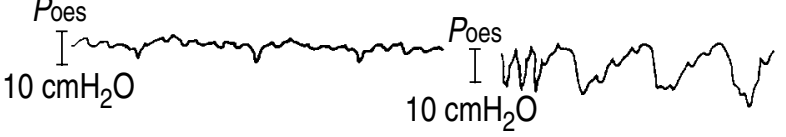

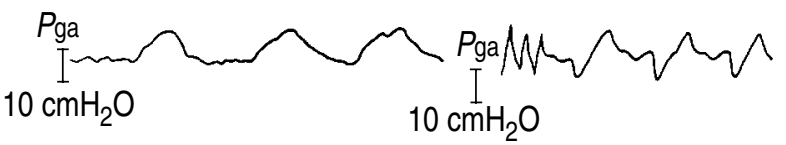

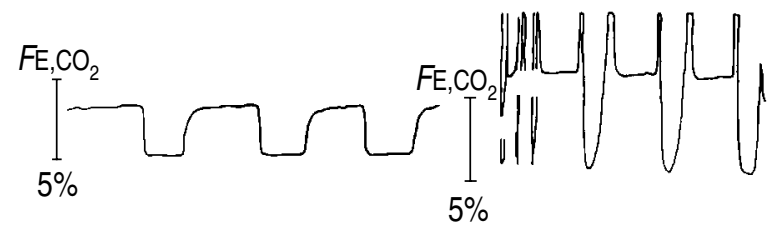

IPPB1 AIR

IPPB1 $\mathrm{CO}_{2}$

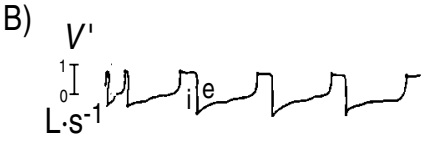

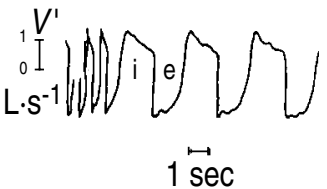

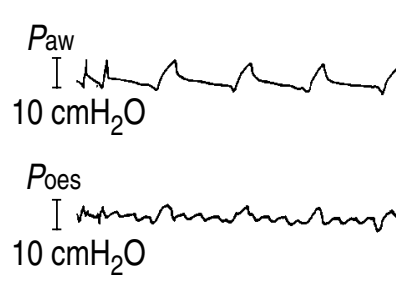

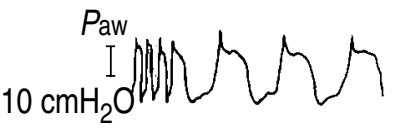

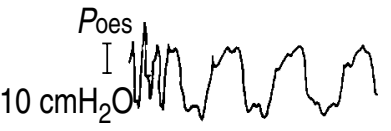<smiles>CCCCCCCCOCCOCCO</smiles>

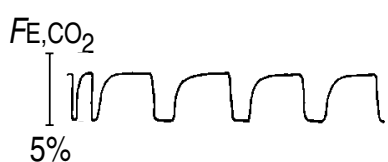

IPPB2 AIR

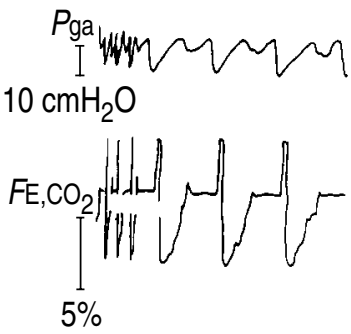

IPPB2 $\mathrm{CO}_{2}$

Fig. 2. - Tracings of flow $\left(V^{\prime}\right)$, airway pressure $(P$ aw $)$, oesophageal pressure $(P$ oes $)$ gastric pressure $(P$ ga $)$, expired fraction of $\mathrm{CO}_{2}\left(F \mathrm{E}, \mathrm{CO}_{2}\right)$, obtained from a representative subject breathing with intermittent positive pressure breathing with a Monaghan 505 apparatus (IPPB1) (A), or an Ohmeda CPU 1 ventilator $(\mathrm{IPPB} 2)(\mathrm{B})$, and $\mathrm{CO}_{2}$-induced hyperventilation $\left(\mathrm{CO}_{2}\right)$. Note the positive expiratory gastric pressure swings during $\mathrm{CO}_{2}$-induced hyperventilation, showing active expiratory muscle recruitment. Inspiration (i) and expiration (e) are indicated in the airflow tracings.

measured was only due to the compression of gas resulting from the action of the expiratory muscles, independently of dynamic hyperinflation. Because this positive alveolar pressure does not constitute an inspiratory load, we subtracted the amount of positive expiratory gastric pressure swing ( $P$ ga,exp) from the dynamic PEEPi measured on the oesophageal pressure tracing, as described recently $[17,18]$. Tracings obtained in a subject who exhibited active expiratory muscle recruitment are shown in figure 2. The work breath $^{-1}$, expressed in Joules (J), was then multiplied by the respiratory rate, to yield the power of breathing $\left(\mathrm{J} \cdot \mathrm{min}^{-1}\right)$. Power was divided by minute ventilation, to obtain work $\cdot \mathrm{L}^{-1}$ of ventilation $\left(\mathrm{J} \cdot \mathrm{L}^{-1}\right)$. Finally, mean inspiratory airway pressure (mean $P$ aw) was calculated for each breath during inspiration.

The mean value of at least 10 breaths was used to perform all the above calculations.

\section{Statistics}

Statistical analysis was carried out by means of a twoway analysis of variance. When the F-value was significant at the 0.05 level, we carried out Tukey's test for paired comparisons. Regression analysis was performed by the least square method. All data are expressed as mean $\pm \mathrm{SD}$, unless otherwise indicated.

\section{Results}

Figures 1 and 2 show the tracings obtained during the eight experimental runs in two representative subjects.

\section{Room air breathing}

Breathing pattern. No differences were noted among the four procedures for respiratory rate or $t \mathrm{I} / t$ tot, but the maximal inspiratory flow was significantly higher $(\mathrm{p}<0.001)$ with the three mechanical devices than during $\mathrm{SB}$, as shown in table 1. Minute ventilation values (fig. 3 ) were significantly lower during SB than during the IPS, IPPB1 or IPPB2 modes $(6.7 \pm 1.5$ versus $11.2 \pm 2.6,13.8 \pm 3.3$, and $11.8 \pm 2.8 \mathrm{~L} \cdot \mathrm{min}^{-1}$, respectively; $\left.\mathrm{p}<0.01\right)$. During $\mathrm{SB}$, $F \mathrm{E}, \mathrm{CO}_{2}$ was significantly higher than during the three assisted breathing modes $(4.7 \pm 0.2$ versus $3.6 \pm 0.5,3.6 \pm 0.2$ and $3.8 \pm 0.2 \% ; \mathrm{p}<0.001)$.

Work of breathing and pressure time product. The power of breathing (fig. 4) and the work $\mathrm{L}^{-1}$ of ventilation (fig. 5) were similar during SB and IPS, but significantly higher with the two IPPB modes $\left(2.4 \pm 0.7 \mathrm{~J} \cdot \mathrm{min}^{-1}\right.$ and $0.35 \pm 0.1 \mathrm{~J} \cdot \mathrm{L}^{-1}$ for $\mathrm{SB}$, and $2.3 \pm 3.3 \mathrm{~J} \cdot \mathrm{min}^{-1}$ and $0.2 \pm 0.2$ $\mathrm{J} \cdot \mathrm{L}^{-1}$ for IPS, versus $7.35 \pm 5.2 \mathrm{~J} \cdot \mathrm{min}^{-1}$ and $0.5 \pm 0.2 \mathrm{~J} \cdot \mathrm{L}^{-1}$ for IPPB1, and 7.2 $\pm 6.2 \mathrm{~J} \cdot \mathrm{min}^{-1}$ and $0.56 \pm 0.2 \mathrm{~J} . \mathrm{L}^{-1}$ for IPPB2; $\mathrm{p}<0.04)$. The PTP, in $\mathrm{cmH}_{2} \mathrm{O} \cdot \mathrm{s} \cdot \mathrm{min}^{-1}$, was $86 \pm 21$ during SB, $52 \pm 36$ during IPS, $136 \pm 75$ during IPPB 1 , and $136 \pm 140$ during IPPB2; $p=0.08$. 
Table 1. - Respiratory rate, duty cycle and flow rate of seven healthy subjects, in four periods of unassisted or assisted breathing, during room air breathing and during $\mathrm{CO}_{2}$-induced hyperventilation

\begin{tabular}{|c|c|c|c|c|c|}
\hline & SB & IPS & IPPB 1 & IPPB2 & p-value \\
\hline \multicolumn{6}{|c|}{ Room air breathing } \\
\hline $\begin{array}{l}\text { Respiratory rate } \\
\text { breaths } \cdot \mathrm{min}^{-1}\end{array}$ & $15 \pm 2$ & $15 \pm 2$ & $14 \pm 2$ & $14 \pm 2$ & NS \\
\hline$t \mathrm{I} / t$ tot $\%$ & $41 \pm 2$ & $34 \pm 5$ & $41 \pm 5$ & $36 \pm 8$ & NS \\
\hline$V^{\prime} \mathrm{I}, \max \quad \mathrm{L} \cdot \mathrm{min}^{-1}$ & $26 \pm 2 *$ & $70 \pm 10$ & $72 \pm 13$ & $54 \pm 10 * *$ & 0.0001 \\
\hline \multicolumn{6}{|c|}{$\mathrm{CO}_{2}$-induced hyperventilation } \\
\hline $\begin{array}{l}\text { Respiratory rate } \\
\text { breaths } \cdot \mathrm{min}^{-1}\end{array}$ & $19 \pm 2$ & $18 \pm 2$ & $18 \pm 2$ & $16 \pm 2$ & NS \\
\hline$t \mathrm{I} / t$ tot $\%$ & $45 \pm 2$ & $45 \pm 2$ & $44 \pm 2$ & $52 \pm 5^{* *}$ & 0.001 \\
\hline$V^{\prime} \mathrm{I}, \max \mathrm{L} \cdot \mathrm{min}^{-1}$ & $74 \pm 20 *$ & $105 \pm 13^{+}$ & $93 \pm 23^{+}$ & $69 \pm 13$ & 0.0003 \\
\hline
\end{tabular}

Values are presented as mean \pm SD. SB: spontaneous breathing; IPS: inspiratory pressure support; IPPB 1 : intermittent positive pressure breathing (Monaghan 505); IPPB2: intermittent positive pressure breathing (Ohmeda CPU 1$) ; t \mathrm{I} / t$ tot: ratio of inspiratory time to total cycle duration; $V^{\prime} \mathrm{I}$,max: maximal inspiratory flow rate. *: significantly different from IPS and IPPB1; **: significantly different from SB, IPS and IPPB 1 ; $^{+}$: significantly different from IPPB2.

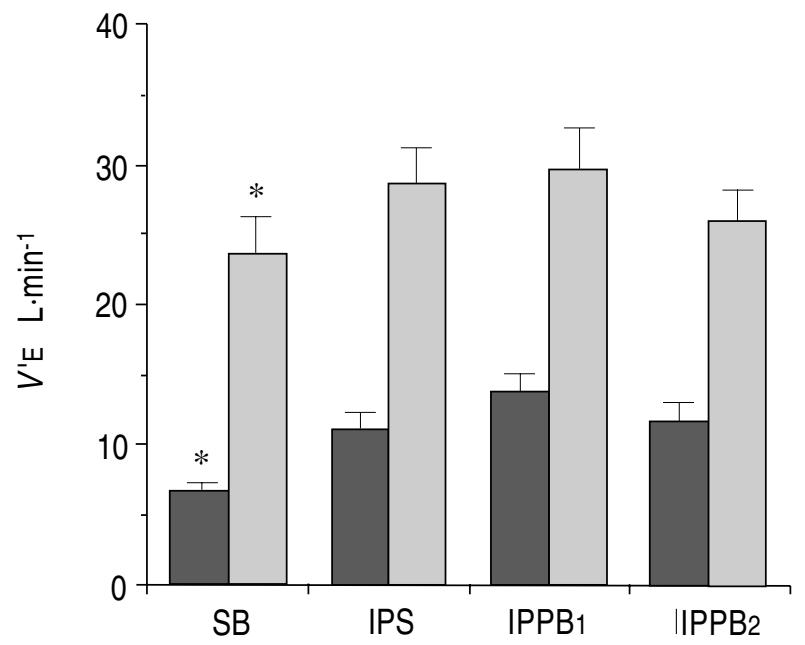

Fig. 3. - Minute ventilation ( $\left.V^{\prime} \mathrm{E}\right)$ during four periods of unassisted breathing (SB: spontaneous breathing) or assisted breathing using inspiratory pressure support (IPS) or intermittent positive pressure breathing with a Monaghan 505 apparatus (IPPB1) or an Ohmeda CPU 1 ventilator (IPPB 2$)$. Values are presented as mean \pm SEM. During spontaneous breathing ( $\square$ ), an asterisk denotes a value significantly different from IPS, IPPB 1 and IPPB2 $(\mathrm{p}<0.01)$; during $\mathrm{CO}_{2}$-induced hyperventilation $(\square)$, an asterisk denotes a value significantly different from IPS and IPPB $1(\mathrm{p}<0.041)$.

A significant difference in mean $P$ aw was found between IPS and the two IPPB modes (IPS 6.8 \pm 0.5 , IPPB $15.0 \pm 1.5$, and IPPB2 $\left.3.8 \pm 1.3 \mathrm{cmH}_{2} \mathrm{O} ; \mathrm{p}<0.001\right)$.

Diaphragmatic activity, comfort and haemodynamics. No significant difference was noted between the four procedures for PEEPi, $P$ di or $P$ ga,exp (table 2). Comfort was significantly poorer $(\mathrm{p}<0.001)$ with the two IPPB devices than with IPS or SB. There was no difference between the four procedures with respect to heart rate,

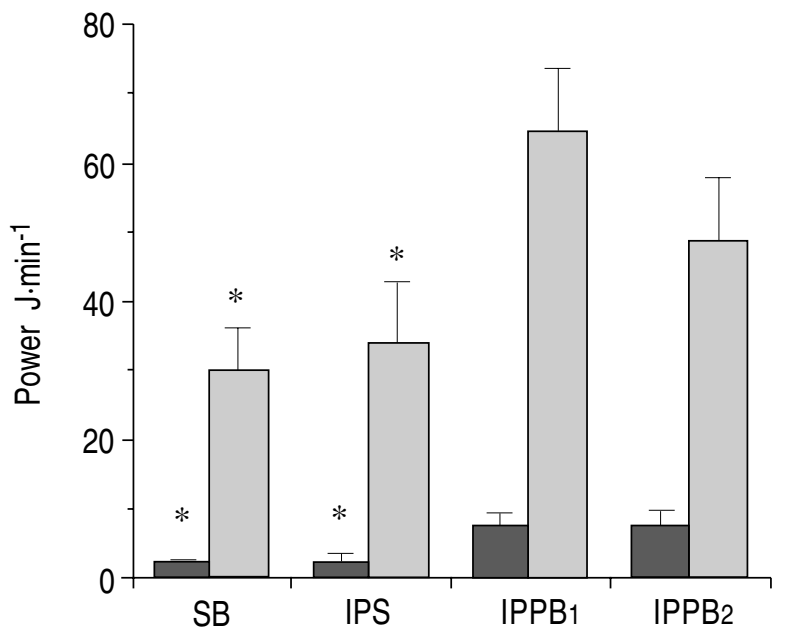

Fig. 4. - Power of breathing during four periods of unassisted breathing (SB: spontaneous breathing) or assisted breathing using inspiratory pressure support (IPS) or intermittent positive breathing with a Monaghan 505 apparatus (IPPB1) or an Ohmeda CPU 1 ventilator (IPPB2). Values are presented as mean \pm SEM. During room air breathing ( $\square$ ), an asterisk denotes a value significantly different from IPPB 1 and IPPB2 $(\mathrm{p}=0.02)$. During $\mathrm{CO}_{2}$-induced hyperventilation ( $\square$ ), an asterisk denotes a value significantly different from IPPB 1 and IPPB $_{2}(\mathrm{p}<0.001)$.

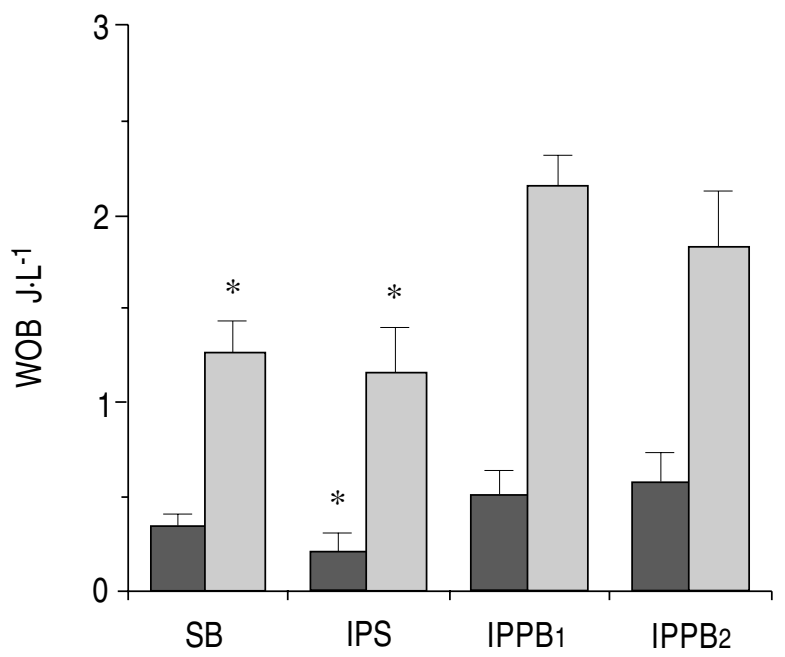

Fig. 5. - Work of breathing (WOB) per litre of ventilation during four periods of unassisted breathing (SB: spontaneous breathing) or assisted breathing using inspiratory pressure support (IPS) or intermittent positive pressure breathing with a Monaghan 505 apparatus (IPPB1) or an Ohmeda CPU 1 ventilator (IPPB2). Values are presented as mean \pm SEM. During room air breathing ( $\square$ ), an asterisk denotes values significantly different from IPPB1 and IPPB2 $(p=0.03)$. During $\mathrm{CO}_{2}$-induced hyperventilation $(\square)$, an asterisk denotes a value significantly different from IPPB1 and $\operatorname{IPPB}_{2}(\mathrm{p}<0.001)$.

which ranged from $65 \pm 8$ to $69 \pm 5$ beats $\cdot \mathrm{min}^{-1}$ (bpm), systolic blood pressure $(111 \pm 8$ to $113 \pm 13 \mathrm{mmHg})$, or diastolic blood pressure $(68 \pm 8$ to $71 \pm 5 \mathrm{mmHg})$.

\section{$\mathrm{CO}_{2}$-induced hyperventilation}

Breathing pattern. There was no difference between the four procedures as regards respiratory rate (table 1 ). $t \mathrm{t} / \mathrm{t}$ tot was significantly greater with IPPB2 than with the three 
Table 2. - Transdiaphragmatic and gastric pressure, PEEPi and comfort of seven healthy subjects in four periods of unassisted or assisted breathing, during room air breathing and during $\mathrm{CO}_{2}$-induced hyperventilation

\begin{tabular}{|c|c|c|c|c|c|}
\hline & SB & IPS & IPPB 1 & IPPB2 & p-value \\
\hline \multicolumn{6}{|c|}{ Room air breathing } \\
\hline$P$ di $\quad \mathrm{cmH}_{2} \mathrm{O}$ & $9 \pm 2$ & $8 \pm 2$ & $10 \pm 2$ & $11 \pm 2$ & NS \\
\hline$P$ ga,exp $\quad \mathrm{cmH}_{2} \mathrm{O}$ & 0 & 0 & $0.1 \pm 0.2$ & 0 & NS \\
\hline PEEPi $\mathrm{cmH}_{2} \mathrm{O}$ & 0 & 0 & $0.9 \pm 1.8$ & $0.6 \pm 1.6$ & NS \\
\hline Comfort & $9.8 \pm 0.2 *$ & $9.1 \pm 1 *$ & $6.1 \pm 2.8$ & $7.2 \pm 2$ & 0.001 \\
\hline \multicolumn{6}{|c|}{$\mathrm{CO}_{2}$-induced hyperventilation } \\
\hline$P \mathrm{di} \quad \mathrm{cmH}_{2} \mathrm{O}$ & $22 \pm 2 *+$ & $18 \pm 2 *$ & $32 \pm 5$ & $28 \pm 5$ & 0.001 \\
\hline$P$ ga,exp $\quad \mathrm{cmH}_{2} \mathrm{O}$ & $2.5 \pm 1.8 *$ & $2.2 \pm 1.3 *$ & $6.7 \pm 4.1$ & $6.2 \pm 3.1$ & 0.001 \\
\hline PEEPi $\quad \mathrm{cmH}_{2} \mathrm{O}$ & $1.0 \pm 0.8$ & $1.7 \pm 1.6$ & $3.3 \pm 2.8$ & $1.4 \pm 1.8$ & NS \\
\hline Comfort & $6.8 \pm 1.8 *$ & $6.5 \pm 2 *$ & $3.1 \pm 2.8$ & $4.1 \pm 1.8$ & 0.001 \\
\hline
\end{tabular}

Values are presented as mean \pm sD. Pdi: transdiaphragmatic pressure; $P$ ga,exp: expiratory swings in gastric pressure; PEEPi: intrinsic positive end-expiratory pressure. For further abbreviations see legend to table 1. *: significantly different from IPPB1 and IPPB2; +: significantly different from IPS.

other modes, and the maximal inspiratory flow measured during IPS and IPPB1 was significantly higher than with $\mathrm{IPPB} 2$ and $\mathrm{SB} . \quad \mathrm{FE}, \mathrm{CO}_{2}$ ranged between $6.2 \pm 0.5$ and $6.7 \pm 0.5 \%$ during the different modes (NS), and minute ventilation was higher during hypercapnia than during room air breathing. As shown in figure 3, minute ventilation was slightly but still significantly higher during IPS and IPPB1 than during SB (28.7 \pm 5 and $29.8 \pm 8$ versus $\left.23.7 \pm 8 \mathrm{~L} \cdot \mathrm{min}^{-1} ; \mathrm{p}=0.04\right)$.

Work of breathing and pressure time product. Power of breathing was 6-12 times higher during $\mathrm{CO}_{2}$-induced hyperventilation than during room air breathing. Again, significant differences existed between the modes. As shown in figures 4 and 5 , the highest values for power and work per litre of ventilation were measured with IPPB1 and IPPB2, for which these indices were significantly higher than with IPS or SB $\left(64.8 \pm 22 \mathrm{~J} \cdot \mathrm{min}^{-1}\right.$ and $2.14 \pm 0.2 \mathrm{~J} \cdot \mathrm{L}^{-1}$ for IPPB 1 , and $48.7 \pm 23 \mathrm{~J} \cdot \mathrm{min}^{-1}$ and $1.82 \pm 0.8$ $\mathrm{J} \cdot \mathrm{L}^{-1}$ for IPPB2 versus $29.9 \pm 15 \mathrm{~J} \cdot \mathrm{min}^{-1}$ and $1.25 \pm 0.5 \mathrm{~J} \cdot \mathrm{L}^{-1}$ for SB and 33.9 $\pm 22 \mathrm{~J} \cdot \mathrm{min}^{-1}$ and $1.15 \pm 0.5 \mathrm{~J} \cdot \mathrm{L}^{-1}$ for IPS; $\mathrm{p}<0.001)$. The PTP, expressed in $\mathrm{cmH}_{2} \mathrm{O} \cdot \mathrm{s} \cdot \mathrm{min}^{-1}$, was significantly lower during SB and IPS $(361 \pm 144$ and $333 \pm 175$, respectively) than during IPPB 1 and IPPB2 (619 \pm 168 and 642 \pm 347 , respectively, $\mathrm{p}<0.001)$.

Mean $P$ aw was positive during IPS, but became negative during IPPB modes $\left(4.7+0.8 \mathrm{cmH}_{2} \mathrm{O}\right.$ for IPS versus $-2.8 \pm 1.6$ for IPPB1 and $-4.5 \pm 0.5$ for IPPB2; $<<0.001$ ), as can be seen in figure 6 , indicating that with IPPB 1 and IPPB2 the demand considerably exceeded the flow supplied by the machines.

Diaphragmatic activity, comfort and haemodynamics. $P$ di was significantly lower during IPS than during SB and both IPPB modes (table 2). Pdi reached the highest values with IPPB1 and IPPB2. Values of positive expiratory gastric pressure swings were higher with the two IPPB modes than with SB and IPS (table 2). The values for dynamic PEEPi were small during the four periods, and did not differ significantly from each other (table 2). Various degrees of discomfort were noted by the subjects, the two worse situations being IPPB 1 and IPPB2 (table 2). Significant negative correlations were observed between comfort and $P$ di $(\mathrm{r}=-0.60 ; \mathrm{p}<0.01)$, and comfort and power of breathing $(\mathrm{r}=-0.53 ; \mathrm{p}<0.01)$.

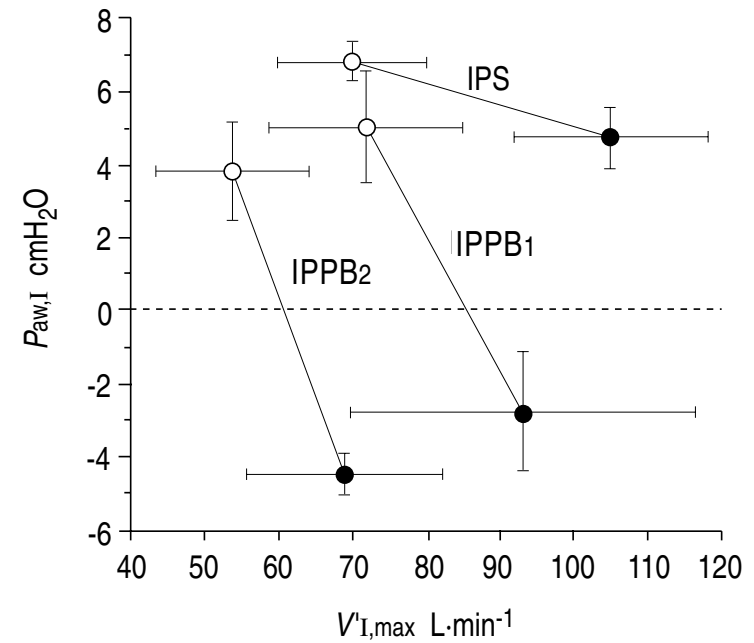

Fig. 6. - Plots of the averaged values of mean inspiratory airway pressure $(P$ aw,I $)$ versus maximum inspiratory flow $\left(V^{\prime} \mathrm{I}, \mathrm{max}\right)$ for the three mechanical devices. Note that when maximal inspiratory flow was reached during $\mathrm{CO}_{2}$-hyperventilation, mean airway pressure dropped considerably with IPPB devices. O: room air; $\bullet \mathrm{CO}_{2}$.

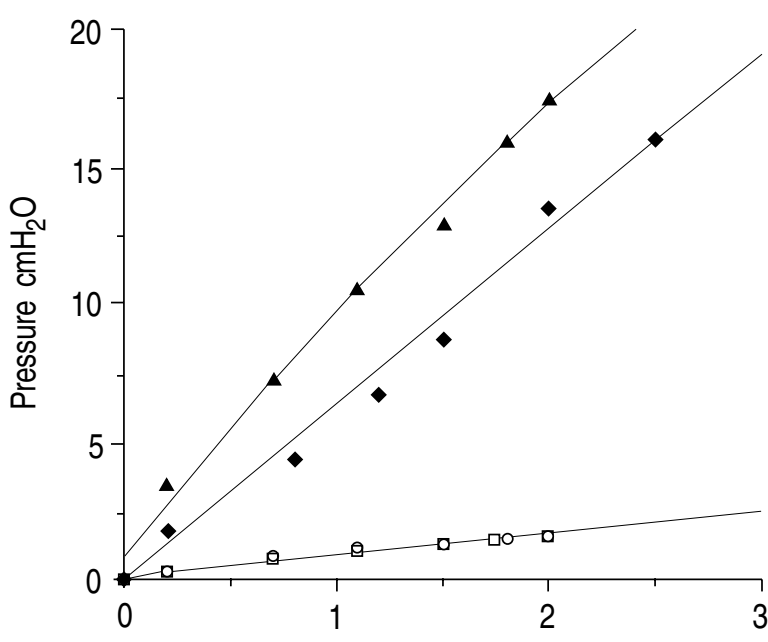

Flow L.S ${ }^{-1}$

Fig. 7. - Pressure flow relationships measured within the expiratory line, and expiratory resistance of the four systems used: unassisted spontaneous breathing (SB) and assisted breathing with inspiratory pressure support (IPS) or with intemittent positive prssure breathing with a Monaghan 505 apparatus (IPPB1) or an Ohmeda CPU 1 ventilator (IPPB2). घ: SB; O: IPS; $\mathbf{\Delta}$ : IPPB1; $\bullet$ : IPPB2. 
All haemodynamic values for SB, IPS, IPPB1, and IPPB2 were higher than those for room air breathing $(\mathrm{p}<0.05)$. Heart rate ranged from $90 \pm 8 \mathrm{bpm}$ during $\mathrm{IPPB}_{1}$ to $82 \pm 10$ bpm during IPS $(\mathrm{p}=0.04)$. Systolic and diastolic blood pressure, respectively, ranged from $138 \pm 16$ to $127 \pm 13$ $\mathrm{mmHg}$ (NS), and from $83 \pm 16$ to $80 \pm 5 \mathrm{mmHg}$ (NS).

Expiratory resistance of the circuits. Expiratory circuit resistance was computed in vitro for each apparatus by plotting the pressure drop across the circuit at various levels of expiratory flow. The pressure-flow relationships for the circuits are depicted in figure 7. For an airflow rate of $1 \mathrm{~L} \cdot \mathrm{s}^{-1}$, circuit resistances (expressed in $\mathrm{cmH}_{2} \mathrm{O} \cdot \mathrm{L} \cdot \mathrm{s}^{-1}$ ) were as follows: 0.9 during $\mathrm{SB}, 0.9$ during IPS, 9.6 during IPPB1, and 5.6 during IPPB2.

\section{Discussion}

In this study, we found that in normal non-intubated subjects the effects of IPS and two IPPB devices on the work of breathing were clearly different. These differences were considerably exaggerated during $\mathrm{CO}_{2}$-induced hyperventilation. The IPPB devices not only failed to reduce patient's effort but also induced a substantial amount of extra workload, compared to unassisted breathing. When IPS was set at a pressure of $10 \mathrm{cmH}_{2} \mathrm{O}$, it induced a level of work similar to that observed with spontaneous breathing, and allowed the reduction of transdiaphragmatic pressure during $\mathrm{CO}_{2}$-induced hyperventilation.

The aim of this study was not to demonstrate that one apparatus designed for ventilatory assistance was better than another, but to stress the importance of the differences in technical design as regards their physiological effects. In the present study, one can argue that the particular devices selected to deliver IPPB were not, among all IPPB devices, the optimal ones. In addition, a fixed setting during the two periods was selected for the study and a different set-up could lead to different effects on work of breathing. Noninvasive ventilation is now commonly proposed as a means of resting the respiratory muscles of patients with respiratory insufficiency $[19,20]$, either to replace home ventilation through tracheostomy [21], or to avoid the need for intubation in patients with acute exacerbation of chronic obstructive disease [9] or other causes of acute respiratory failure [8]. Both favourable clinical results $[8,9,22]$ and unfavourable results $[23,24]$ have been reported for patients with acute respiratory failure. However, the efficacy of such systems as regards the changes in physiological parameters was not reported in the latter studies [23, 24].

Although commonly available IPPB devices could be used in acute respiratory failure, we found here that their efficacy was very different from IPS, despite similarities in their working principles. We observed that the IPPB apparatus considerably increased the effort required for spontaneous ventilation and induced great discomfort, whereas the IPS machine did not. Such results suggest that the use of inadequate systems for patients with severe dyspnoea may considerably worsen respiratory failure.
This may potentially happen with any device which has not been rigorously tested in these conditions, and may explain an apparent inefficacy of noninvasive ventilation with such devices.

IPS and IPPB systems present several technical differences [25]. These differences are related to: the trigger variable (what starts inspiration); the limit variable (what sustains inspiration); and the cycle variable (what ends inspiration). IPPB1 and IPPB2 are pressure-triggered whereas IPS is flow-triggered. The limit variable is pressure in IPS, whereas it is flow in IPPB2; there is no real limit variable during inspiration in IPPB1, although the maximal flow capacity of the ventilator constitutes a constraint. The cycle variable is pressure in both IPPB devices, and flow in IPS; this characteristic can impose an active expiratory effort to raise airway pressure [3, 26]. The IPS and IPPB 1 both delivered a descending ramp flow, whereas IPPB2 delivered a pulse flow. The expiratory resistances were also different among the devices, being much higher with the two IPPB machines, as can be seen in figure 7 .

When patients have high ventilatory requirements, as occurred during $\mathrm{CO}_{2}$-induced hyperventilation, a high initial flow rate may be an important determinant of comfort and may affect respiratory drive [14, 16, 27, 28]. In intubated patients, an inadequate inspiratory flow pattern with a low peak flow relative to patient's demand induces excessive inspiratory work of breathing and pressuretime product [29]. An inappropriately low inspiratory flow may also impair lung inflation and increase the $t \mathrm{I} / t$ tot [30], as observed during $\mathrm{CO}_{2}$-induced hyperventilation with the IPPB2 device, which is a flow-limited mode. However, with the IPS and IPPB1 devices, peak flow rates were not significantly different. Despite this, considerable differences in comfort and respiratory muscle work were found between the two devices. It therefore suggests that other factors may influence these differences. With IPPB circuits, greater impedance to airflow was likely, as suggested by the greater airway pressure drop during inspiration and the greater intensity of subjects' effort. During $\mathrm{CO}_{2}$-induced hyperventilation, mean inspiratory $P$ aw was negative with the two IPPB devices, thus indicating that the flow needed by the subjects far exceeded the flow provided by the ventilator. Figure 5 illustrates the fact that the increase in flow requirements, as generated during the period of hyperventilation, induced a drop in mean inspiratory $P$ aw with IPPB devices, whereas it remained positive with IPS.

The fact that the expiratory resistances of both IPPB circuits were much higher than that of the IPS circuit probably affected our results. It has been suggested that an increase in the flow impeding characteristics of expiratory valves augment the inspiratory work of breathing [31]. Furthermore, high expiratory resistance can magnify the sensation of dyspnoea. Dynamic hyperinflation resulting in relevant PEEPi levels may be observed with IPPB devices as a result of high expiratory circuit resistance, and increase the elastic load. We did not observe such an effect here because all subjects were free of lung disease. 
During $\mathrm{CO}_{2}$-induced hyperventilation, active expiratory work was present, and was intensified with the IPPB circuits. Previous studies also showed that active expiratory work was induced by these circuits [3, 26], and the cycling mechanism from inspiration to expiration may play a role in this expiratory effort. In our study, recruitment of the abdominal muscles during expiration was suggested by the positive expiratory swings observed on gastric pressure tracings, and the higher values observed for expiratory $P$ ga with both IPPB machines with regards to IPS and unassisted breathing, suggest that IPPB enhanced expiratory muscle recruitment [18, 32].

Comfort was satisfactory during spontaneous breathing and IPS, but was considerably poorer with both IPPB modes. The increases both in inspiratory work and expiratory muscle activity might contribute to the greater sensation of dyspnoea described by the subjects during IPPB, and may lead to a lack of synchrony between the subject and the ventilator. During $\mathrm{CO}_{2}$-induced hyperventilation, the level of comfort correlated better with the indices of inspiratory muscle activity, i.e. $P \mathrm{di}$ and power of breathing ( $r=-0.60$ and -0.53 , respectively; $\mathrm{p}<0.01$ for both) than with the expiratory swings in gastric pressure $(\mathrm{r}=0.38 ; \mathrm{p}=0.04)$. This suggests that inspiratory effort was the main cause of discomfort. If systems such as IPPB are to be proposed for spontaneously breathing patients with acute respiratory failure, any worsening of dyspnoea induced by the device should be avoided. Additionally, the higher level of comfort during IPS indicates that this type of assistance is more appropriate for dyspnoeic subjects.

We arbitrarily selected a preset pressure level of 10 $\mathrm{cmH}_{2} \mathrm{O}$, because higher levels of IPPB have been poorly tolerated in some patients [1]. In the light of previous data concerning intubated $[10,12,33,34]$ or nonintubated patients [9] with acute respiratory failure, the selected level of IPS was relatively low and probably insufficient to meet the subjects' demand. The level of IPS was almost entirely used to overcome circuit resistance.

In conclusion, we found in this study that, in normal subjects, several ventilatory assistance devices, based on similar principles but using different mechanisms for delivering assistance, had different effects on respiratory muscle activity. When ventilatory demand was great, the two IPPB machines considerably worsened inspiratory muscle work and discomfort, even compared to unassisted spontaneous breathing, whereas IPS assistance better matched patient's demand.

\section{References}

1. Kamat SR, Dulfano MJ, Segal MB. The effects of intermittent positive pressure breathing (IPPB/I) with compressed air in patients with severe chronic nonspecific obstructive pulmonary disease. Am Rev Respir Dis 1962; 86: $360-380$.

2. Ayres SM, Kozam RL, Lukas DS. The effects of intermittent positive pressure breathing on intrathoracic pressure, pulmonary mechanics, and the work of breathing. Am Rev Respir Dis 1963; 87: 370-379.
3. Sukumalchantra Y, Park SS, Williams MH Jr. The effects of intermittent positive pressure breathing (IPPB) in acute ventilatory failure. Am Rev Respir Dis 1965; 92: 885-893.

4. The Intermittent Positive Pressure Breathing Trial group. Intermittent positive pressure breathing therapy of chronic obstructive pulmonary disease: a clinical trial. Ann Intern Med 1983; 99: 612-620.

5. De Troyer A, Deisser P. The effects of intermittent positive pressure breathing on patients with respiratory muscle weakness. Am Rev Respir Dis 1981; 124: 132-137.

6. Celli BR, Rodriguez KS, Snider GL. A controlled trial of intermittent positive pressure breathing, incentive spirometry and deep breathing exercises in preventing pulmonary complications after abdominal surgery. Am Rev Respir Dis 1984; 130: 12-15.

7. McCool FD, Mayewski RF, Shayne DS, Gibson CJ, Griggs RC, Hyde RW. Intermittent positive pressure breathing in patients with respiratory muscle weakness: alterations in total respiratory system compliance. Chest 1986; 90: 546-552.

8. Meduri GU, Conoscenti CC, Menashe P, Nair S. Noninvasive face mask ventilation in patients with acute respiratory failure. Chest 1989; 95: 865-870.

9. Brochard L, Isabey D, Piquet J, et al. Reversal of acute exacerbations of chronic obstructive lung disease by inspiratory assistance with a face mask. N Engl J Med 1990; 323: $1523-1530$.

10. MacIntyre NR. Respiratory function during pressure support ventilation. Chest 1986; 89: 677-683.

11. Brochard L, Pluskwa F, Lemaire F. Improved efficacy of spontaneous breathing with inspiratory pressure support. Am Rev Respir Dis 1987; 136: 411-415.

12. Brochard L, Harf A, Lorino H, Lemaire F. Inspiratory pressure support prevents diaphragmatic fatigue during weaning from mechanical ventilation. Am Rev Respir Dis 1989; 139: 513-521.

13. Baydur A, Behrakis PK, Zin WA, Jaeger M, Milic-Emili J. A simple method for assessing the validity of the esophageal balloon technique. Am Rev Respir Dis 1982; 126: 788-791.

14. Bradley TD, Chartrand DA, Fitting JW, Killian KJ, Grassino A. The relation of inspiratory effort sensation of fatiguing patterns of the diaphragm. Am Rev Respir Dis 1986; 134: 1119-1124.

15. Roussos C, Campbell EJM. Respiratory muscle energetics. In: Handbook of physiology, Section 3, Vol. 3: Respiration. Bethesda, American Physiological Society, 1986; pp. 481-509.

16. Fleury B, Murciano D, Talamo C, Aubier M, Pariente R, Milic-Emili J. Work of breathing in patients with chronic obstructive pulmonary disease in acute respiratory failure. Am Rev Respir Dis 1985; 131: 822-827.

17. Appendini L, Patessio A, Zanaboni S, et al. Physiologic effects of positive end-expiratory pressure and mask pressure support during exacerbations of chronic obstructive pulmonary disease. Am J Respir Crit Care Med 1994; 149: 1069-1076.

18. Lessard M, Lofaso F, Brochard L. Expiratory muscle activity increases intrinsic positive end-expiratory pressure independently of dynamic hyperinflation. Am $J$ Respir Crit Care Med 1995; 151: 562-569.

19. Carroll N, Branthwaite MA. Intermittent positive pressure ventilation by nasal mask: technique and applications. Intens Care Med 1988; 14: 115-117.

20. Carrey JR, Gottfried SB, Levy RD. Ventiatory muscle support in respiratory failure with nasal positive pressure ventilation. Chest 1990; 97: 150-158. 
21. Bach JR, Alba A, Mosher R, Delaubier A. Intermittent positive pressure ventilation via nasal access in the management of respiratory insufficiency. Chest 1987; 92: 168-170.

22. Meduri GU, Abou-Shala N, Fox RC, Jones CB, Leeper $\mathrm{KV}$, Wundeink RG. Noninvasive face mask mechanical ventilation in patients with acute hypercapnic respiratory failure. Chest 1991: 100: 445-454.

23. Chevrolet JC, Jolliet P, Abajo B, Toussi A, Louis M. Nasal positive pressure ventilation in patients with acute respiratory failure: difficult and time-consuming procedure for nurses. Chest 1991; 100: 775-782.

24. Foglio C, Vitacca M, Quadri A, Scalvini S, Marangoni $\mathrm{S}$, Ambrosino N. Acute exacerbations in severe COLD patients: treatment using positive pressure ventilation by nasal mask. Chest 1992; 101: 1533-1538.

25. Chatburn RL. Classification of mechanical ventilators. In: Tobin MJ, ed. Principles and Practice of Mechanical Ventilation. New York, McGraw-Hill, 1994; pp. 37-64.

26. Jones RH, McNamara J, Gaensler EA. The effects of intermittent positive pressure breathing on simulated pulmonary obstruction. Am Rev Respir Dis 1960; 82: 164-185.

27. Tobin MJ, Chadha TS, Jenouri G, Birch SJ, Gazeroglu HB, Sackner MA. Breathing patterns. 1. Normal subjects. Chest 1983; 84: 202-205.
28. Marini JJ, Capps JS, Culver BH. The inspiratory work of breathing during assisted mechanical ventilation. Chest 1985; 87: 612-618.

29. Ward ME, Corbeil C, Gibbons W, Newman S, Macklem PT. Optimization of respiratory muscle relaxation during mechanical ventilation. Anesthesiology 1988; 69: 29-35.

30. Altose MD, Kelsen SG, Stanley NN, Levinson RS, Cherniack NS, Fishman AP. Effects of hypercapnia on mouth pressure during airway occlusion in conscious man. J Appl Physiol 1976; 40: 338-344.

31. Banner MJ, Downs JB, Kirby RR, Smith RA, Boysen PG, Lampotang S. Effects of expiratory flow resistance on expiratory work of breathing. Chest 1988; 93 : 795-799.

32. Ninane V, Rypens F, Yernault JC, De Troyer A. Abdominal muscle use during breathing in patients with chronic airflow obstruction. Am Rev Respir Dis 1992; 146: 16-21.

33. Fiastro JF, Habib MP, Quan SF. Pressure support compensation for inspiratory work due to endotracheal tubes and demand continuous positive airway pressure. Chest 1988; 93: 499-505.

34. Brochard L, Rua F, Lorino H, Lemaire F, Harf A. Inspiratory pressure support compensates for the extra work of breathing induced by the endotracheal tube. Anesthesiology 1991; 75: 739-745. 